\title{
Effect of modified atmospheric packaging on shelf-life of Cham-cham
}

\author{
Rohit SindhaV*1, D.H. Patel ${ }^{2}$, A.M. Patel ${ }^{2}$ and P.S. Prajapati ${ }^{1}$ \\ ${ }^{1}$ Department of Dairy Technology, S.M.C. College of Dairy Science, ANAND (GUJARAT) INDIA \\ ${ }^{2}$ Department of Dairy Processing and Operations, S.M.C. College of Dairy Science, ANAND (GUJARAT) INDIA \\ Email : rohitsindhav7@gmail.com
}

*Author for Correspondence

Research chronicle : Received : 29.09.2016; Revised : 20.10.2016; Accepted : 22.11.2016

\begin{abstract}
SUMMARY :
The present study was carried out to evaluate the shelf-life of Cham-Cham using modified atmospheric packaging (MAP). Cham-Cham stored under refrigeration temperature $\left(7 \pm 2^{\circ} \mathrm{C}\right)$ in modified atmospheric condition showed significantly higher shelf-life than the Cham-Cham stored at same temperature in normal packaging condition. The compositional attributes such as fat, protein, total carbohydrate and ash of Cham-Cham increased significantly where as moisture was significantly decreased up on storage at $7 \pm 2^{\circ} \mathrm{C}$. The acidity and soluble nitrogen content where non-significantly increased. However, $\mathrm{pH}$ of Cham-Cham decreased significantly on storage at $7 \pm 2^{\circ} \mathrm{C}$. FFA and HMF content of Cham-Cham increased significantly when Cham-Cham stored at $7 \pm 2^{\circ} \mathrm{C}$. The packages were found to have a significant increased in the hardness, chewiness and cohesiveness. However, significant decreased in the adhesiveness and springiness values of Cham-Cham were found at $7 \pm 2^{\circ} \mathrm{C}$ storage temperature. However stiffness of Cham-Cham increased non-significantly at $7 \pm 2^{\circ} \mathrm{C}$. The flavour, body and texture, colour and appearance and overall acceptability scores of ChamCham declined significantly as storage period progressed. Hence, the shelf-life of Cham-Cham extended up to 28 days in MAP as compare to normal packaging shows up to 14 days. It also shows that the use of $\mathrm{CO}_{2}$ was superior to $\mathrm{N}_{2}$ in MAP.
\end{abstract}

KEY WORDS : Modified atmospheric packaging, Cham-Cham, Shelf-life, FFA, HMF

How to cite this paper : Sindhav, Rohit, Patel, D.H., Patel, A.M. and Prajapati, P.S. (2016). Effect of modified atmospheric packaging on shelf-life of Cham-cham. Internat. J. Proc. \& Post Harvest Technol., 7 (2) : 228-236.

DOI: 10.15740/HAS/IJPPHT/7.2/228-236. 